https://journal.unfias.ac.id/index.pfip/jmsk/index

Vol. 17, No. 3, 349-356, May, 2021

DOI: $10.20956 /$ j.v17i3.12490

\title{
Solving Ordinary Differential Equation Using Parallel Seventh Order Runge-Kutta Method with Two Processors
}

\section{Penyelesaian Persamaan Diferensial Biasa Menggunakan Metode Runge- Kutta Orde Ketujuh Paralel dengan Dua Prosesor}

\begin{abstract}
Iman Al Fajri ${ }^{1 *}$, Hendra ${ }^{2 *}$, Jeffry Kusuma ${ }^{3 *}$
Abstract

This paper presents a derivation of the seventh order Runge-Kutta method with eight stages suitable for parallel implementation. The development of a parallel model is based on the second type of Runge-Kutta sparsity structure which is divided into two processors by creating a semi-implicit version of the sequential seventh order Runge-Kutta which is solved through nine stages. The parallelization simulation implementation uses the Ray module in the Python programming language by giving a 0.01 second delay for each completed stage. Comparison of the calculation of the parallel model and the sequential model in terms of accuracy shows the same results, even in some cases, parallel is better. It is generally seen that the parallel method will approach the analytical solution by increasing the number of iterations. In terms of execution time, parallel method has advantage over sequential method.
\end{abstract}

Keywords : Seventh Order Runge-Kutta Method, Parallel Algorithm, Sequential Algorithm

\begin{abstract}
Abstrak
Makalah ini menyajikan penurunan dari metode Runge-Kutta orde ketujuh dengan delapan tahapan yang cocok untuk implementasi secara paralel. Pengembangan model paralel didasarkan pada struktur sparsity Runge-Kutta tipe kedua yang dibagi ke dalam dua prosesor dengan membuat versi semi implisit dari Runge-Kutta orde ketujuh sekuensial yang diselesaikan melalui sembilan tahapan. Implementasi simulasi paralelisasi menggunakan modul Ray pada bahasa pemrograman Python dengan memberi delay 0.01 detik untuk setiap tahapan yang diselesaikan. Perbandingan perhitungan model paralel dan model sekuensial dari sisi akurasi menunjukkan hasil yang sama, bahkan pada beberapa kasus, paralel lebih baik. Terlihat secara umum bahwa metode paralel akan mendekati solusi analitik dengan meningkatkan jumlah iterasi. Ditinjau dari sisi waktu eksekusi, metode paralel memiliki keunggulan dibandingkan dengan metode sekuensial.
\end{abstract}

Kata kunci : Metode Runge-Kutta Orde Ketujuh, Algoritma Paralel, Algoritma Sekuensial

\section{Pendahuluan}

Algoritma paralel adalah salah satu metode untuk menyelesaikan masalah numerik. Masalah numerik merupakan salah satu masalah yang memerlukan kecepatan komputasi yang cukup tinggi. Dalam ilmu komputer, sebuah algoritma paralel atau algoritma bersamaan, sebagai lawan sekuensial, merupakan algoritma yang dapat dieksekusi sepotong pada suatu waktu dan pada banyak perangkat

\footnotetext{
* Program Studi Magister Matematika, FMIPA-UNHAS

Email: ${ }^{1}$ iman.alfajri@gmail.com, ${ }^{2}$ hendra.unhas@gmail.com, ${ }^{3}$ jeffry.kusuma@gmail.com

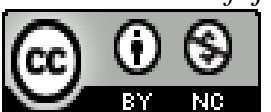

This work is licensed under a Creative Commons Attribution-NonCommercial 4.0 International License 


\section{Jumal Matematika, Statistika \& Komputasi Iman Al Fajri, Hendra, Jeffry Kusuma}

pengolahan yang berbeda, kemudian digabungkan bersama-sama lagi sehingga didapatkan hasil yang benar.

Ada tingkatan paralelisme yang bisa digunakan untuk memecahkan persamaan diferensial biasa secara numerik. Caranya adalah dengan restrukturisasi kode manual dan/atau kompilator paralelisasi. Ini dapat ditambah dengan mengganti serial dengan paralel, misalnya, aljabar linier. Namun, levellevel paralelisasi ini mungkin tidak diharapkan menghasilkan banyak perbaikan karena banyak kode mungkin masih harus berjalan secara serial. Pendekatan yang lebih bermanfaat adalah mendesain ulang sifat sekuensial dari algoritma yang digunakan untuk memecahkan persamaan diferensial biasa menjadi algoritma paralel.

Metode Runge-Kutta adalah salah satu metode penyelesaian persamaan diferensial dengan nilai awal secara numerik. Metode ini dapat menghasilkan solusi yang memiliki akurasi yang cukup tinggi dibandingkan dengan metode lainnya.

Dalam banyak kasus, persamaan diferensial tidak dapat dipecahkan dalam aspek analitik. Tujuannya adalah untuk menemukan di antara metode yang ada, metode terbaik untuk resolusi numerik. Juga untuk memfasilitasi penerapan metode dengan memperkenalkan perangkat lunak penghitungan. Untuk melakukan ini, digunakan metode Runge-Kutta yang merupakan salah satu metode resolusi numerik terbaik [10].

Publikasi [3] menganalisis hubungan koefisien metode Runge-Kutta orde ketiga dan orde keempat. Hasilnya adalah metode paralel dapat secara bersamaan memenuhi hubungan koefisien kedua metode tersebut. Metode ini dapat diimplementasikan dalam kerangka multi-proses berdasarkan cluster. Metode tersebut diterapkan pada simulasi numerik integral prediksi orbit pesawat ruang angkasa. Hasil eksperimen menunjukkan bahwa keakuratan metode paralel konsisten dengan metode serial, dan kecepatan komputasi secara signifikan lebih tinggi daripada metode serial.

Implementasi efisien dari metode Runge-Kutta implisit untuk menyelesaikan sistem besar persamaan diferensial biasa dilakukan dengan memanfaatkan blok segitiga bawah dari matriks kuadratur dan mengilustrasikannya secara numerik [1,5,9]. Runge-Kutta implisit diagonal diterapkan pada persamaan diferensial biasa orde pertama dengan menggunakan Runge-Kutta orde keempat sampai orde keenam dengan dua sampai tujuh tahapan [7].

\section{Metode Runge-Kutta Orde Ketujuh Paralel}

Bentuk umum persamaan diferensial biasa orde pertama dengan nilai awal adalah

$$
y^{\prime}(x)=f(x, y), \quad y\left(x_{0}\right)=y_{0} .
$$

Bentuk umum metode Runge-Kutta s-tahap untuk masalah (2.1) didefinisikan sebagai [4]

$$
y_{n+1}=y_{n}+h \sum_{i=1}^{s} b_{i} k_{i}
$$

di mana

$$
k_{i}=f\left(x_{n}+c_{i} h, y_{n}+h \sum_{j=1}^{s} a_{i j} k_{j}\right), \quad i, j=1,2, \ldots, s
$$

dengan mengasumsikan sebagai berikut. 


\section{Jumal Matematika, Statistika \& Komputasi \\ Iman Al Fajri, Hendra, Jeffry Kusuma}

$$
c_{i}=\sum_{j=1}^{s} a_{i j}, \quad i, j=1,2, \ldots, s
$$

Koefisien pada persamaan (2.2) dan (2.3) dapat ditampilkan dengan menggunakan tabel Butcher sebagai berikut [2].

Tabel 2.1. Tabel Butcher

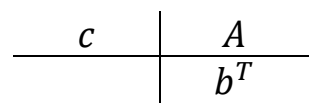

Untuk metode Runge-Kutta orde ketujuh dengan 9-tahap dirumuskan sebagai berikut.

$$
y_{n+1}=y_{n}+h \sum_{i=1}^{9} b_{i} k_{i}
$$

Sedangkan solusi eksak untuk persamaan (2.5) adalah

$$
Y_{i}=y\left(x_{0}+h \sum_{i=1}^{9} a_{i j}\right)+O\left(h^{2}\right)
$$

Koefisien pada persamaan (2.2) dan (2.3) direprentasikan dengan Array Butcher atau Tabel Butcher seperti pada Tabel 2.2 berikut.

Tabel 2.2. Tabel Butcher 9-tahap Orde Ketujuh

\begin{tabular}{c|ccccccccc}
$c_{1}$ & $a_{11}$ & & & & & & & & \\
$c_{2}$ & $a_{21}$ & $a_{22}$ & & & & & & & \\
$c_{3}$ & $a_{31}$ & $a_{32}$ & $a_{33}$ & & & & & \\
$c_{4}$ & $a_{41}$ & $a_{42}$ & $a_{43}$ & $a_{44}$ & & & & \\
$c_{5}$ & $a_{51}$ & $a_{52}$ & $a_{53}$ & $a_{54}$ & $a_{55}$ & & & & \\
$c_{6}$ & $a_{61}$ & $a_{62}$ & $a_{63}$ & $a_{64}$ & $a_{65}$ & $a_{66}$ & & & \\
$c_{7}$ & $a_{71}$ & $a_{72}$ & $a_{73}$ & $a_{74}$ & $a_{75}$ & $a_{76}$ & $a_{77}$ & & \\
$c_{8}$ & $a_{81}$ & $a_{82}$ & $a_{83}$ & $a_{84}$ & $a_{85}$ & $a_{86}$ & $a_{87}$ & $a_{88}$ & \\
$c_{9}$ & $a_{91}$ & $a_{92}$ & $a_{93}$ & $a_{94}$ & $a_{95}$ & $a_{96}$ & $a_{97}$ & $a_{98}$ & $a_{99}$ \\
\hline & $b_{1}$ & $b_{2}$ & $b_{3}$ & $b_{4}$ & $b_{5}$ & $b_{6}$ & $b_{7}$ & $b_{8}$ & $b_{9}$
\end{tabular}

Metode ini dikatakan eksplisit jika $a_{i j}=0$ untuk $i \leq j$, semi implisit jika $a_{i j}=0$ untuk $i<j$, selain itu dikatakan sepenuhnya implisit. Kajian ini secara khusus membahas tentang metode RungeKutta dengan sifat semi implisit.

Rumusan Runge-Kutta orde ketujuh serial [2] menggunakan metode dengan 9 tahapan sebagai berikut.

Tabel 2.3. Tabel Butcher 9-tahap Orde Ketujuh Sekuensial

$$
\begin{array}{l|l}
0 & \\
\frac{1}{6} & \frac{1}{6}
\end{array}
$$




\section{Jurnal Matematika, Statistika \& Komputasi}

Iman Al Fajri, Hendra, Jeffry Kusuma

\begin{tabular}{|c|c|c|c|c|c|c|c|c|c|}
\hline 1 & 0 & 1 & & & & & & & \\
\hline$\overline{3}$ & 0 & $\overline{3}$ & & & & & & & \\
\hline 1 & 1 & 0 & 3 & & & & & & \\
\hline$\overline{2}$ & $\overline{8}$ & & $\overline{8}$ & & & & & & \\
\hline 2 & 148 & 0 & 150 & 56 & & & & & \\
\hline$\overline{11}$ & $\overline{1331}$ & 0 & $\overline{1331}$ & $\overline{1331}$ & & & & & \\
\hline 2 & -404 & 0 & 170 & 4024 & 10648 & & & & \\
\hline$\overline{3}$ & $-\overline{243}$ & 0 & $-\overline{27}$ & $\overline{1701}$ & $\overline{1701}$ & & & & \\
\hline 6 & 2466 & 0 & 1242 & 19176 & 51909 & 1053 & & & \\
\hline$\overline{7}$ & $\overline{2401}$ & 0 & 343 & $\overline{16807}$ & $\overline{10807}$ & $\overline{2401}$ & & & \\
\hline 0 & 5 & 0 & 0 & 96 & 1815 & 405 & 49 & & \\
\hline & $\overline{154}$ & & & $\overline{539}$ & $\overline{20384}$ & $\overline{2464}$ & $\overline{144}$ & & \\
\hline 1 & -113 & 0 & 195 & 32 & 29403 & 729 & 1029 & 21 & \\
\hline & $/ 32$ & 0 & $-\frac{22}{22}$ & 7 & 3584 & $\overline{512}$ & $\overline{1408}$ & $\overline{16}$ & \\
\hline & 0 & 0 & 0 & $\frac{32}{105}$ & 1771561 & 243 & 16807 & 77 & 11 \\
\hline
\end{tabular}

\section{Metode Paralel Tipe II}

Tabel Butcher untuk metode orde keenam tipe II diberikan oleh Tabel 3.1 berikut [2].

Tabel 3.1. Tabel Butcher 8-tahap Orde Ketujuh Tipe II

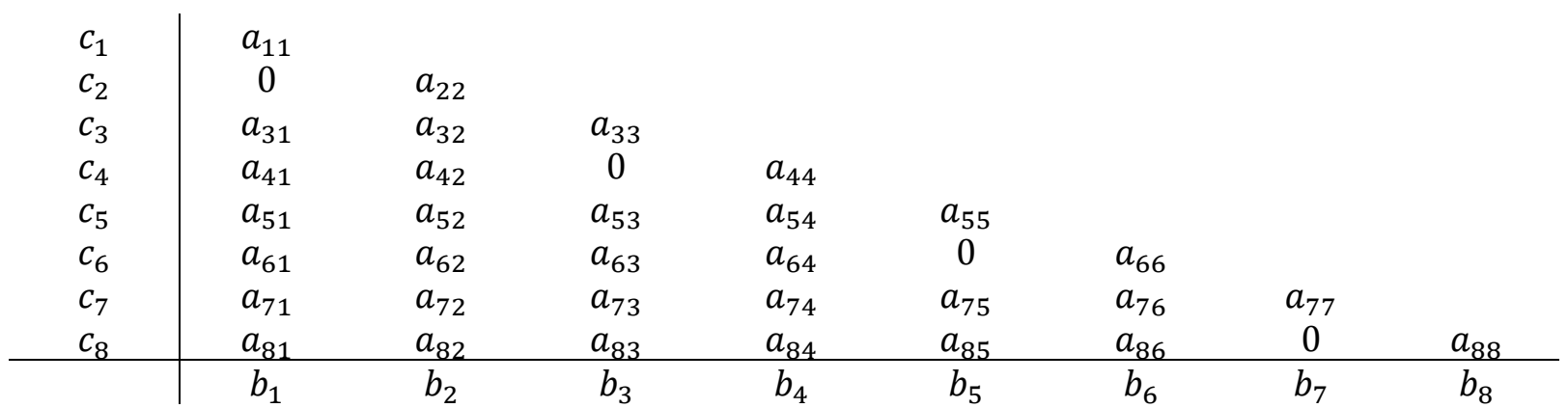

Struktur ketersebaran metode tipe II diperluas untuk mendapatkan metode Runge-Kutta orde tinggi yang merupakan orde ketujuh dengan delapan evaluasi fungsional. Struktur baru disajikan pada Gambar 3.1 bersama dengan digrafnya [6].

\section{Matriks Runge-Kutta}

$$
\left(\begin{array}{llllllll}
x & 0 & 0 & 0 & 0 & 0 & 0 & 0 \\
0 & x & 0 & 0 & 0 & 0 & 0 & 0 \\
x & x & x & 0 & 0 & 0 & 0 & 0 \\
x & x & 0 & x & 0 & 0 & 0 & 0 \\
x & x & x & x & x & 0 & 0 & 0 \\
x & x & x & x & 0 & x & 0 & 0 \\
x & x & x & x & x & x & x & 0 \\
x & x & x & x & x & x & 0 & x
\end{array}\right)
$$

Digraf

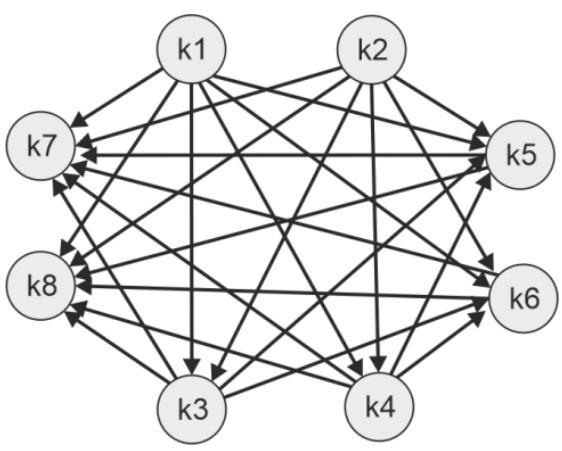




\section{Jumal Matematika, Statistika \& Komputasi}

\section{Iman Al Fajri, Hendra, Jeffry Kusuma}

Gambar 3.1. Struktur Ketersebaran dan Digraf untuk Metode RungeKutta Orde Ketujuh dengan Delapan Tahapan

Formulasi Runge-Kutta untuk tabel Butcher 8-tahap orde ketujuh Tipe II tersebut adalah

$$
y_{n+1}=y_{n}+h \sum_{i=1}^{8} b_{i} k_{i}
$$

di mana

$$
\begin{aligned}
& k_{1}=f\left(x_{n}+c_{1} h, y_{n}+h\left(a_{11} k_{1}\right)\right) \\
& k_{2}=f\left(x_{n}+c_{2} h, y_{n}+h\left(a_{22} k_{2}\right)\right) \\
& k_{3}=f\left(x_{n}+c_{3} h, y_{n}+h\left(a_{31} k_{1}+a_{32} k_{2}+a_{33} k_{3}\right)\right) \\
& k_{4}=f\left(x_{n}+c_{4} h, y_{n}+h\left(a_{41} k_{1}+a_{42} k_{2}+a_{44} k_{4}\right)\right) \\
& k_{5}=f\left(x_{n}+c_{5} h, y_{n}+h\left(a_{51} k_{1}+a_{52} k_{2}+a_{53} k_{3}+a_{54} k_{4}+a_{55} k_{5}\right)\right) \\
& k_{6}=f\left(x_{n}+c_{6} h, y_{n}+h\left(a_{61} k_{1}+a_{62} k_{2}+a_{63} k_{3}+a_{64} k_{4}+a_{66} k_{6}\right)\right) \\
& k_{7}=f\left(x_{n}+c_{7} h, y_{n}+h\left(a_{71} k_{1}+a_{72} k_{2}+a_{73} k_{3}+a_{74} k_{6}+a_{75} k_{5}+a_{76} k_{6}+a_{77} k_{7}\right)\right) \\
& k_{8}=f\left(x_{n}+c_{8} h, y_{n}+h\left(a_{81} k_{1}+a_{82} k_{2}+a_{83} k_{3}+a_{84} k_{6}+a_{85} k_{5}+a_{86} k_{6}+a_{88} k_{8}\right)\right)
\end{aligned}
$$

Untuk mendapatkan metode Runge-Kutta orde ketujuh paralel 8 tahapan, digunakan rumusan metode Runge-Kutta sekuensial pada Tabel 2.2 yang diubah menjadi diagonal semi implisit. Sehingga diperoleh persamaan sebagai berikut.

$$
y_{n+1}=y_{n}+h\left(0 k_{1}+0 k_{2}+\frac{32}{105} k_{3}+\frac{1771561}{6289920} k_{4}+\frac{243}{2560} k_{5}+\frac{16807}{74880} k_{6}+\frac{77}{1440} k_{7}+\frac{11}{270} k_{8}\right)
$$

di mana

$$
\begin{aligned}
& k_{1}=f\left(x_{n}+h\left(\frac{1}{6}\right), y_{n}+h\left(\frac{1}{6}\right) k_{1}\right) \\
& k_{2}=f\left(x_{n}+h\left(\frac{1}{3}\right), y_{n}+h\left(\frac{1}{3}\right) k_{2}\right) \\
& k_{3}=f\left(x_{n}+h\left(\frac{1}{2}\right), y_{n}+h\left(\frac{1}{8}\right) k_{1}+h(0) k_{2}+h\left(\frac{3}{8}\right) k_{3}\right) \\
& k_{4}=f\left(x_{n}+h\left(\frac{2}{11}\right), y_{n}+h\left(\frac{148}{1331}\right) k_{1}+h\left(\frac{150}{1331}\right) k_{2}+h\left(-\frac{56}{1331}\right) k_{4}\right) \\
& k_{5}=f\left(x_{n}+h\left(\frac{2}{3}\right), y_{n}+h\left(-\frac{404}{243}\right) k_{1}+h(0) k_{2}+h\left(-\frac{170}{27}\right) k_{3}+h\left(\frac{4024}{1701}\right) k_{4}\right. \\
& \left.\quad+h\left(\frac{10648}{1701}\right) k_{5}\right) \\
& \quad+h\left(-\frac{6}{10807}\right), y_{n}+h\left(\frac{2466}{2401}\right) k_{1}+h\left(\frac{1242}{343}\right) k_{2}+h\left(-\frac{19176}{16807}\right) k_{3}
\end{aligned}
$$




\section{Jumal Matematika, Statistika \& Komputasi}

\section{Iman Al Fajri, Hendra, Jeffry Kusuma}

$$
\begin{aligned}
k_{7}=f\left(x_{n}+\right. & h(0), y_{n}+h\left(\frac{5}{154}\right) k_{1}+h(0) k_{2}+h(0) k_{3}+h\left(\frac{96}{539}\right) k_{4}+h\left(-\frac{1815}{20384}\right) k_{5} \\
& \left.+h\left(-\frac{405}{2464}\right) k_{6}+h\left(\frac{49}{144}\right) k_{7}\right) \\
k_{8}=f\left(x_{n}+h\right. & (1), y_{n}+h\left(-\frac{113}{32}\right) k_{1}+h\left(-\frac{195}{22}\right) k_{2}+h\left(\frac{32}{7}\right) k_{3}+h\left(\frac{29403}{3584}\right) k_{4} \\
& \left.+h\left(-\frac{729}{512}\right) k_{5}+h\left(\frac{1029}{1408}\right) k_{6}+h\left(\frac{21}{16}\right) k_{8}\right)
\end{aligned}
$$

Diperoleh rumusan metode Runge-Kutta orde ketujuh dengan 8 tahapan pada persamaan (3.3) dan (3.4) yang siap dipakai untuk menyelesaikan persamaan diferensial. Untuk menguji keandalan metode Runge-Kutta yang ditemukan, akan digunakan pada beberapa kasus di bawah ini.

\section{Beberapa Masalah yang Diuji}

Soal $5.1[8]$ :

$$
\begin{gathered}
y^{\prime}=\cos (2 x), \\
y(0)=4, \quad 0 \leq x \leq 1 .
\end{gathered}
$$

Solusi eksak : $y=\frac{1}{2} \sin (2 x)+4$

Soal $5.2[8]$ :

$$
\begin{gathered}
y^{\prime}=e^{x}(3 \sin 2 x+2 \cos 2 x)-2 y, \\
y(0)=1, \quad 0 \leq x \leq 1 .
\end{gathered}
$$

Solusi Eksak : $y=e^{-2 x}+e^{x} \sin 2 x$

\section{Hasil Perhitungan Numerik}

Tabel 6.1. Nilai Galat Global Maksimum (GGM) Soal 5.1 dan 5.2 antara Metode Paralel dan Metode Sekuensial Dibandingkan dengan Solusi Analitik

\begin{tabular}{llcccc}
\hline \multirow{6}{*}{ Soal } & \multirow{6}{c}{ Metode } & \multicolumn{4}{c}{ GGM } \\
\cline { 3 - 6 } & & $h=10^{-1}$ & $h=10^{-2}$ & $h=10^{-3}$ & $h=10^{-4}$ \\
\hline \multirow{3}{*}{5.1} & RK4 Sekuensial & $5.062616992 \mathrm{E}-14$ & $1.243449788 \mathrm{E}-14$ & $1.687538997 \mathrm{E}-14$ & $8.082423619 \mathrm{E}-14$ \\
& RK4 Paralel & $5.062616992 \mathrm{E}-14$ & $1.243449788 \mathrm{E}-14$ & $1.687538997 \mathrm{E}-14$ & $8.082423619 \mathrm{E}-14$ \\
& & & & & \\
\hline & & & & & \\
5.2 & RK4 Sekuensial & $7.481309556 \mathrm{E}-02$ & $7.892880887 \mathrm{E}-03$ & $7.931475369 \mathrm{E}-04$ & $7.935300051 \mathrm{E}-05$ \\
& RK4 Paralel & $1.837075818 \mathrm{E}-02$ & $1.548182798 \mathrm{E}-03$ & $1.528469541 \mathrm{E}-04$ & $1.526537343 \mathrm{E}-05$ \\
& & & & & \\
\hline
\end{tabular}

Selanjutnya Tabel 6.2 dan 6.3 menunjukkan waktu eksekusi sekuensial dan paralel untuk masingmasing masalah yang diselesaikan. Proses ini menggunakan komputer dengan spesifikasi intel core i3 yang diatur untuk menggunakan dua prosesor dengan memori 4 (empat) GB. Paralelisasi diatur dengan modul Ray dari bahasa pemrograman Python.

Perhitungan diimplementasikan pada algoritma paralel dan diberikan waktu delay 0.01 detik untuk setiap persamaan yang dieksekusi. Hal ini bertujuan untuk menerapkan konsep paralelisasi yang telah digambarkan pada Tabel 3.1. Waktu delay 0.01 detik juga diterapkan pada algoritma sekuensial sebagai pembandingnya. 


\section{Jumal Matematika, Statistika \& Komputasi \\ Iman Al Fajri, Hendra, Jeffry Kusuma}

Tabel 6.2. Waktu Eksekusi untuk Soal 5.1

\begin{tabular}{cccc}
\hline$h$ & $n$ & $\begin{array}{c}\text { Waktu Eksekusi Sekuensial } \\
(\text { detik })\end{array}$ & $\begin{array}{c}\text { Waktu Eksekusi Paralel } \\
(\text { detik })\end{array}$ \\
\hline $10^{-1}$ & 10 & 0.827968 & 0.682974 \\
\hline $10^{-2}$ & 100 & 7.668562 & 5.774143 \\
\hline $10^{-3}$ & 1000 & 76.615609 & 58.392098 \\
\hline $10^{-4}$ & 10000 & 755.883317 & 558.092867 \\
\hline & & Tabel 6.3. Waktu Eksekusi untuk Soal 5.2 \\
\hline $10^{-1}$ & 10 & Waktu Eksekusi Sekuensial & Waktu Eksekusi Paralel \\
$($ detik) & (detik) \\
\hline $10^{-2}$ & 100 & 7.6863380 & 0.6645990 \\
$10^{-3}$ & 1000 & 76.2234060 & 6.1695970 \\
$10^{-4}$ & 10000 & 752.7016530 & 55.7306180 \\
\hline
\end{tabular}

\section{Kesimpulan}

Perbandingan nilai galat global maksimum antara metode sekuensial, paralel, dan solusi analitik adalah bahwa metode Runge-Kutta orde ketujuh paralel menunjukkan akurasi yang sama dibandingkan dengan metode sekuensial. Dalam beberapa kasus, akurasi paralel lebih baik daripada sekuensial. Secara umum bahwa dari seluruh soal yang diselesaikan, metode Runge-Kutta orde ketujuh paralel sudah mendekati nilai perhitungan solusi analitik apabila iterasinya semakin ditingkatkan.

Perbandingan waktu eksekusi, percepatan, dan efisiensi algoritma sekuensial dan algoritma sekuensial terlihat bahwa untuk setiap peningkatan jumlah iterasi, waktu eksekusi paralel lebih baik daripada waktu eksekusi sekuensial.

\section{Daftar Pustaka}

[1] Axelsson, O, dan Neytcheva, M. 2020. Numerical Solution Methods for Implicit Runge-Kutta Methods of Arbitrarily High Order. In: Proceedings of the conference 'Algoritmy 2020' Vydavatel'stvo SPEKTRUM, Slovak University of Technology in Bratislava, Vol. 7, pp. 11-20

[2] Butcher, J.C. 2008. Numericals Methods for Ordinary Differential Equations Second Edition. 


\section{Jumal Matematika, Statistika \& Komputasi \\ Iman Al Fajri, Hendra, Jeffry Kusuma}

Wiley : USA

[3] Cui, W., Li, Y., dan Sun, Z. 2019. A Parallel Computer Numerical Simulation Method Based on Coincident Coefficients. J. Phys.: Conf. Ser. 1486042038

[4] Din, U.K.S., dan Ismail, F. 2011. Parallel Two-Processor Fifth Order Diagonally Implicit RungeKutta Method. Menemui Matematik, Vol. 33, No. $1: 23$

[5] Hatten, N. dan Russell, R. P. 2017. Parallel Implicit Runge-Kutta Methods Applied to Coupled Orbit/Attitude Propagation. Journal of the Astronautical Sciences, vol. 64, no. 4, pp. 333-360

[6] Iserles, A. dan Nørsett, S. P. 1990. On the Theory of Parallel Runge-Kutta Methods. IMA J. Numer. Anal., vol. 10, no. 4, pp. 463-488

[7] Kennedy, C.A., dan Carpenter, M.H. 2016. Diagonally Implicit Runge-Kutta Methods for Ordinary Differential Equations. A Review. NASA : Virginia

[8] Maya, Rippi. 2014. Diktat Kuliah Persamaan Diferensial Biasa Revisi Keenam. IKIP Siliwangi : Bandung

[9] Pazner, W., dan Persson, P.2017. Stage-parallel fully implicit Runge-Kutta solvers for discontinuous Galerkin fluid simulations. Journal of Computational Physics, Vol. 335

[10] Séka, H. dan Kouassi, A. R. 2019. A New Seventh Order Runge-kutta Family: Comparison with the Method of Butcher and Presentation of a Calculation Software. Math. Comput. Sci., vol. 4, no. 3, p. 68 